\title{
Integration and Coordination of Early Childhood Care and Education in the Republic of Korea
}

\author{
Yoshie Kaga Steven Barnett John Bennett \\ UNESCO
}

\begin{abstract}
UNESCO conducted a cross-national study on the issue of integration of early childhood care and education services within education in 2008-2009. In order to have a more comprehensive understanding of the issue, UNESCO undertook a review on a parallel ECCE system in the Republic of Korea by the request of the Korean Ministry of Education, Science and Technology. In this article, an overview of the Korean ECCE system is provided with a brief appraisal of the quality of the Korean ECCE system by referring to selected quality, access and financing indicators. We highlighted positive developments of the country in recent years and discussed issues and challenges that are directly or indirectly related to integration. The challenges include demographic changes and their implications for the parallel system, and uneven qualifications, training and working conditions of childcare and kindergarten staff. Based on observations during the review visit, we analyzed several integration options and provided related policy recommendations.
\end{abstract}

Key words: integration, early childhood care and education system, the Republic of Korea

\section{Introduction}

Currently, Korea follows a parallel ${ }^{1}$ early childhood care and education (ECCE) policy, governance and delivery system but is keen to explore other options, particularly though not exclusively, a more integrated approach.

\footnotetext{
Correspondence concerning this article should be addressed to Steven Barnett, Director, National Institute for Early Education Research, Rutgers University, USA; John Bennett, Independent Consultant; Yoshie Kaga, Programme Specialist, Division for Basic Learning and Skills Development UNESCO, 7 Place de Fontenoy, 75007 Paris, France. Electronic mail may be sent to y.kaga@unesco.org

*This article is based on the UNESCO's review report on ECCE in the Republic of Korea.
}

Upon the request of the Ministry of Education of the Republic of Korea, UNESCO has conducted a review of the Korean ECCE systems and policies. The request was, at least in part, influenced by the country's exposure to UNESCO's cross-national study Caring and Learning Together: Integration of Early Childhood Care and Education (ECCE) ${ }^{2}$ carried out in 2008-2009. The study examined a policy option of integrating the responsibility for early care and education within the education system, based on the experiences of five countries (Brazil, Jamaica, New Zealand, Slovenia, Sweden) and one municipality (Ghent in Belgium). The study looked at the rationale, process, extent and consequences 
Table 1

Percentage access to early childhood services in selected OECD countries

\begin{tabular}{c|ccccc}
\hline Age in years & Germany & Finland $^{1}$ & France & Korea & Sweden $^{1}$ \\
\hline $0-1$ & $2.6 \%$ & c. $1 \%^{2}$ & $\mathrm{M}$ & $24.3 \%$ & c. $1 \%^{2}$ \\
$1-2$ & $13.6 \%$ & $27.5 \%$ & $\mathrm{M}$ & $44.8 \%$ & $48.9 \%$ \\
$2-3$ & $29.7 \%$ & $43.9 \%$ & $46.4 \%$ & $60.3 \%$ & $91.2 \%$ \\
$3-4$ & $80.4 \%$ & $62.3 \%$ & $98.9 \%$ & $75.0 \%$ & $94.8 \%$ \\
$4-5$ & $93.1 \%$ & $68.5 \%$ & $100.0 \%$ & $84.7 \%$ & $97.3 \%$ \\
$5-6$ & $95.3 \%$ & $73.0 \%$ & $98.7 \%$ & $90.6 \%$ & $98.2 \%$ \\
\hline
\end{tabular}

Source: Eurostat, 2010.

Note 1. In both Finland and Sweden, compulsory school begins at 7 years. Almost $100 \%$ of Finnish children attend pre-school from at age6.

2. Parents in Finland and Sweden enjoy over one year of parental leave, a replacement subsidy of about $70 \%$ of salary (ceiling on high salaries) and very family-friendly work environments. The employment rate of mothers in Sweden is $72 \%$ with children $0-2$ years, and $81 \%$ with children 3-5 years - compared to $29.9 \%$ and $44.9 \%$ respectively in the Republic of Korea (Suh and Kim, 2010). Fertility rates, though not at replacement level, remain high and stable at 1.67 in Sweden since 2004

of integration, and drew lessons and conclusions. It also covered perspectives from countries (Belgium Flanders, France, Finland and Hungary) that have chosen to arrange the responsibility for ECCE differently.

One key lesson from the Caring and Learning Together cross-national study (2010) is that there should be more and deeper studies of integration on a wide range of countries, including countries with parallel systems. The present review, therefore, is a contribution to filling this knowledge gap, while providing concrete policy recommendations that respond to the specific needs and situations of the Republic of Korea.

The UNESCO review has involved three main steps: (1) the preparation of a Background Report, (2) a review visit conducted by a team of experts, and (3) the preparation of a Review Report. The Background Report was prepared by experts of the Korean Institute of
Child Care and Education according to the guidelines, developed by UNESCO.

\section{A Brief Overview of Early Childhood Care and Education in the Republic of Korea}

\section{Access Levels in Childcare and Kindergarten Services}

Several European countries have still the highest rates of early childhood enrolment in the world, but at the present rate of progress, Korea may soon surpass them. Some features of access and enrolments in the Korean ECCE system are as follows (see KICCE, 2010).

As can be seen from the access figure above, the Republic of Korea has high rates of enrolment for children under three years compared to similar European economies. There is a strong and careful investment in childcare services 
and financial supports to parents; but fewer incentives for parental leave and its take-up are available. The underthree enrolment rate is greater than the employment rate of mothers, regardless of the age of the child. This could reflect employment of mothers that is not accounted for in official labour market statistics.

Childcare centres provide places for children 3 months to 5 years inclusive, kindergartens for children 3 years to 5 years inclusive. When age and type of service are taken into account, children up to the age of four years attend childcare facilities more often, while five-year-olds tend to enroll in kindergartens. The highest enrolment in childcare is of 2 year olds, enrolled at $60 \%$ in childcare facilities. Afterwards, the percentage enrolment drops in childcare centres as children from the age of 3 years shift gradually toward kindergartens and hakwons ${ }^{3}$. As in other countries, regional disparities in access exist.

Far more children are enrolled in private services than in public services. In the kindergarten sector, $77.9 \%$ of children are in private kindergartens (although the numbers of public and private kindergartens are about the same) and in the childcare sector, $73.2 \%$ are in private provision and $25.1 \%$ in public or 'authorized' centres. Family daycare accounts for $48.8 \%$ of the children in out-of-home centres. This high share of family daycare for children 3-5 years is high compared to other developed economies. In turn, the small proportion of public childcare services for children, including for the age group 3-5 years, may reduce the capacity of Ministry of Health and Welfare to orient the system.

A downward drift in enrolments has occurred in line with population decline, but the trend has slowed and even reversed in kindergartens since 2007. In particular, kindergarten enrolments of 3-, 4- and 5-year olds continue to rise. Many of the rural kindergartens are attached to schools.

The enrolment rate for 5-year olds in kindergartens currently exceeds $50 \%$ of the children in the age group. This is attributed to causes such as the expansion of the full-day system, improvement of educational capacity and promotional activities, and increased tuition support.

An increasing proportion of kindergarten enrolment is oriented toward the national/public kindergartens (23.4\% of all children in the age group).

\section{Selected Quality Indicators}

The quality of governance sub-systems. Governance sub-systems include policy units, the training and curriculum authorities, monitoring and evaluation agencies, quality assurance systems, inspection and support systems, data collection, monitoring and research. No doubt, criticisms of the functioning of any of the above sub-systems could be made, but they all exist in the Republic of Korea (often in duplicated form) and the contribution of each can be clearly seen. The UNESCO team was impressed, in particular, by the depth of reflexion 
and wealth of data on early childhood matters that KICCE was able to make available.

\section{Attention to learning environments.} This seems to be well addressed in the Republic of Korea as both childcare and kindergarten services receive generous grants for building and/or the refurbishment of centres. In addition, there are subsidies for the purchase of books and pedagogical materials. As in most countries, the provision of appropriate outdoor areas for young children is a challenge in the cities.

Group sizes and child:adult group ratios. In kindergartens, there areno central government regulations on group sizes and teacher-child ratio, which are left to provincial offices of education to set the guidelines so as toaccommodatelocal needs and circumstances. The average teacher-child ratio in kindergartens is 14.8 (2011). On the other hand, teacherchild ratios in childcare centres are set by the age of the child (1:3 for under 1 year olds, 1:5 for 1 year olds, 1:7 for 2 year olds, 1:15 for 3 year olds, 1: 20 for 4 and 5 year olds).

Curriculum as a pedagogical tool. Both childcare and early education have excellent national curricula, appropriate to young children's needs and learning. As part of the implementation of the policy to provide free quality education for all five year olds, a common curriculum called the 'Nuri Curriculum for Age 5' was recently developed. Its release was announced jointly by the Ministries of Health and Welfare, and Education, Science and Technology in September 2011; and its implementation began in March 2012. In January 2012, the Korean government announced its intention to implement the Nuri Curriculum for Ages 3 and 4 starting from March 2013.

Teacher education. At the moment, there are two training and qualification systems in the Republic of Korea, operated by Ministry of Health and Welfarefor childcare centres and childcare preschools; and one operated by Ministry of Education, Science and Technologyfor the kindergarten sector. Childcare teachers are trained through various routes: training programmes for high school graduates (13.5\%); $2 / 3$ year junior college certificates $(67.6 \%)$, college graduation $(17.6 \%)$ and 4-year university graduate degree holders (1.3\%). At the college level, a childcare teacher certificate can be gained from 13 different academic departments, e.g. social welfare $(41 \%)$, early childhood education $(37 \%)$, home economics $(12 \%)$, social work, nursing, psychology, etc. High school graduates receive a Grade-3 certificate and those with a degree in childcare or related field (accounting for $72.8 \%$ of the childcare work force) receive a Grade- 2 certificate.

Kindergarten teachers are educated at 2/3-year junior colleges or 4-year higher education institutions, including universities. About $50 \%$ of the graduatesof junior colleges but almost all candidates 
$(84.3 \%)$ are trained in the early childhood education departments. On graduation, they receive the rank of a Grade-2 teacher. They can be promoted to Grade-1 after three years of experience and a further 180 hours training (22 credits) at a local teacher training centre. Grade-1 teachers make up $27.5 \%$ of the kindergarten teaching corps and Grade$2,59.1 \%$. Most are employed in private kindergartens. The remaining $13 \%$ are directors $(10 \%)$ and assistant directors (3\%) (2011). To be appointed to a public kindergarten, passing an open review process and a competitive public examination is a prerequisite. A position in a public kindergarten is highly coveted as the pay is equal to that of primary and middle school teachers, and one becomes a civil servant with all the attendant advantages.

By international standards, teacher certification in the Republic of Korea including in the childcare sector compares well with most OECD countries. Most teachers - including in family daycare - are college graduates (average 67.2\%), that is, they have a childcare degree or diploma from a 2/3-year college. In addition, $17.6 \%$ are university graduates. Only $13.5 \%$ are no more than high school graduates. Workplace and public centres have the highest proportion (over $80 \%$ ) of Grade 1 teachers.

Quality Assurance Systems. Again, the Republic of Korea is more advanced than many countries in this respect. Both early childhood education and childcare sectors have evaluation systems, introduced in recent years, to ensure that Korea's early childhood care and education systems are providing quality services to children and families. Few countries, to our knowledge, finance and engage in such evaluations to the extent practised in the Republic of Korea.

Since 2006, the childcare sector has a Childcare Facility Accreditation Office and a Childcare Centre Accreditation System (CCAS). In order to be authorised and accredited, all facilities are obliged to undergo evaluation and obtain accreditation. Evaluation consists of a self-report, a basic items check-list, an inspection report and a committee opinion. The inspection includes a comprehensive review of business registration, standards for providing educational materials and facilities, childcare staff qualifications and employment, curriculum implementation, facility status, accounting reports, etc. A self-evaluation report must be sent annually to the website of the Evaluation Office at the Korean Childcare Promotion Institute. Out of a total of 41,349 facilities, $78.4 \%$ have passed the evaluation and thus gained accreditation (2012). It is useful to note that $93.1 \%$ of public facilities have succeeded; followed by $74.5-80 \%$ of family daycare and private facitilies; and $36.5 \%$ of parent co-ops. In general, childcare centres are eager to obtain accreditation through CCAS, since an accredited status - which is made visible for visitors of successful centres through the accreditation board fosters parents' trust and influences 
their decision to send their children to these centres.

The Kindergarten Evaluation System (KES) was introduced in 2007. Evaluation areas include curriculum, educational environment, health and safety, operations management and parent satisfaction. The KES evaluators include college professors, directors, and deputy directors of public and private kindergartens. Each kindergarten must submit an internal evaluation report, which then is verified by site inspection and a written evaluation by the evaluation team. An independent panel combines the results of the two evaluations and delivers a comprehensive evaluation report to the kindergarten. Evaluation results are released to the public; and the authorities promote the identification and dissemination of successful kindergarten operations found through the KES. A later revision of the KES evaluation allows the substitution of the written evaluation by the kindergarten's own education plan and internal evaluation report. From our standpoint, this is a potential improvement as it allows room for internal evaluation and documentation. Objections by private kindergartens delayed the evaluation of all kindergartens until 2010. A lesson to be learned is that private, for-profit services will not necessarily agree to the raising of quality standards.

\section{Positive Developments in Recent Years}

The UNESCO team was impressed by a number of positive developments found in the area of ECCE in the
Republic of Korea in the recent years. For example, there is almost full coverage of 5-year-olds, and the participation of young children of all ages is increasing. This trend has been due mainly to the adoption of the government policy to provide free early education for 5-year-olds in 1999 for the first time, as well as to the more recent expansion of childcare and private provision.

Ongoing efforts for improving the quality and coherence of ECCE services are visible and encouraging. For example, subsidies for private childcare and kindergarten teachers which began in 1990, are said to have lifted teachers' morale and encouraged enhanced practices. The introduction of a national early childhood care curriculum in the childcare sector in 2007 and establishment of an accreditation system for childcare centres in 2004 are concrete signs of the Ministry of Health and Welfare's commitment to improving the quality of childcare services.

The development of a common curriculum for 5-year-olds - which was mandated by the government under the leadership of President Lee Myung-bak in 2011 - is meant to provide all children with the same quality of early education across various childcare and kindergarten providers. Not only will there be more coherence across services for children age 5, but also the initiative is bringing the Ministry of Health and Welfare and the Ministry of Education, Science and Technolgy together around the same table to dialogue and cooperate for a shared goal. The curriculum called the Nurri Curriculum 
- meaning the 'world' in Korean - was developed and finalized in August 2011, and will be rolled out in March 2012. The two Ministries still have to work out how to provide training to existing and new childcare and kindergarten teachers on the common curriculum and how curriculum implementation is to be supported and monitored in both sectors.

Increasingly, parental needs for extended hours of childcare are being met. This has been made possible largely by the rise in the number of full day kindergartens, which started in the mid-1990s. As kindergartens began to provide childcare service in the afternoon, working parents whose children are in kindergartens have been freed from the necessity to look for and secure a convenient and suitable childcare arrangement after the kindergarten hours.

Positive results have been evident in the Yeong Cha Project ${ }^{4}$, initiated in 2009 and implemented by the Korean Institute of Child Care and Education (Moon, et al., 2009). The Project aims to (1) identify types and characteristics of cooperation between childcare services and kindergartens, and (2) specify the methods, scope, level and procedures of the cooperation between these institutions. It has convincingly shown the value of cooperation between childcare services and kindergartens. The Project brings childcare centres and kindergartens together, giving them opportunities to learn about what their counterpart does, to cooperate in designing and implementing joint activities, and to share resources. The UNESCO team was informed of the following positive outcomes:

- Childcare and kindergarten teachers and directors understanding each other better;

- Childcare and kindergarten teachers and directors learning from each other' approaches and practices;

- Childcare and kindergarten carrying out joint planning for common areas and themes of interest;

- Childcare and kindergarten children interact, mingle and socialize together by participating in common activities (e.g. field trips), benefiting from opportunities to acquire caring attitudes and behaviours vis-à-vis younger children and to nurture their social skills;

- Childcare services and kindergartens being able to save costs by pooling their material and financial resources, e.g. to hire specialist speakers for parenting education sessions; to share a garden or outdoor play area, etc; and

- Local officials in charge of childcare and kindergarten sectors talking to each other and working together.

However, it was made clear that the workload of teachers and directors has increased due to their involvement in the Yeong Cha Project, since it requires time to communicate and co-ordinate actions between the two types of establishments. It was suggested that in order to continue the Project, incentives 
for participating in such services should be considered.

\section{An Analysis of the Integration Issues Encountered}

\section{The Concepts 'Care ' and 'Education' in the Parallel System}

The discourses of 'Care' and 'Education' pronounced by different stakeholders were at times confusing to the UNESCO team. The phrase that care is for the younger children and that education can begin from three was repeatedly heard. Meanwhile, there seems to be some agreement, at least among some stakeholders in both sectors, that they provide both 'care' and 'education' (or 'educare').

One can suppose that the confusion is partly caused by the ambiguous nature of the term 'care.' It can mean both 'providing alert supervision of the child that is nurturing, safe and healthy so that the parents can work', and 'expressing a personal interest in and fostering a warm relationship and emotional bond with the child'. Korean stakeholders may be using the term 'care' to mean the former in some cases while the latter in others. There is also the difficulty - encountered in most countries - of theorising and practising an educational relationship with young children that does not subjugate the child but supports child agency and genuine meaning making while taking into account the curricular requirements.
Looking at the national kindergarten curriculum and the standard childcare curriculum, the conceptual disagreement that surfaces at the discourse level between those working in the childcare sector and those in the kindergarten sector seems to disappear.

From an economic point of view, there is recognition that ECCE delivers two different products: childcare and education. In other words, ECCE is a policy field in which care and education are necessarily produced together educating a child requires providing care, and caring for a child requires providing education. Nevertheless, to limit costs, trade-offs may be made by governments either limiting the hours to pay for higher quality or increasing hours at the expense of lower educational quality. If parents vary in their relative desire for long hours or greater educational quality, then they may wish to be offered choices of ECCE with different emphases. However, as parents differ in their ability to purchase ECCE based on their incomes, this choice can exacerbate inequality in educational opportunities and later economic success unless subsidies and other policies equalize opportunities.

It is important to be shared firmly among all stakeholders - be they parents, teachers, providers or policymakersthat education begins at birth and that children develop and learn in their very first years, which are critical for socioemotional development, self-regulation, language development, and initial socialization. Education should not be a narrow concept (like academic training) 
to be monopolized by the education sector, but is to be understood in a broad sense, necessitating good physical and mental health care and involving learning to be, learning to do, learning to learn, learning to live together, which comprise the 'four pillars of learning' as put forward by the UNESCO Delors Report (1996). At the same time, 'care' as understood as nurture and protection for well-being and warm and responsive relationship - fosters motivation to learn and to achievemeaningful learning and later academic success. This suggests the importance of investing in the upgrading of quality - particularly educational quality - of numerous family daycare units and small childcare services.

\section{Demographic Trends and Their Impact on the Parallel System}

The Republic of Korea has the lowest total fertility rate among OECD countries, which has alarmed Korean policymakers. With a total fertility rate of 1.24 (2011) well below the replacement level of 2.1 births per female, there is growing concern about how to support the country's elderly in an aging society. It was clear that the Korean government's priorities included both redressing the declining birth rate and promoting women's labour market participation. Meanwhile, the number of school-age children is also decreasing, which frees up some of the resources that the Ministry of Education currently allocates to primary and secondary education. A research paper recently prepared for the Ministry of Education, Science and Technology reports that the number of elementary school students, which is now $3,122,000$, is projected to drop to 2,931,000 next year, falling below 3 million for the first time since the government began reporting this figure in 1965 .

It would seem that the implications of the population shift in the Republic of Korea are different for the education and health/welfare sectors. The Ministry of Education, Science and Technology has declining pressures on its budget (from this source) and a declining population to serve. This provides the Ministry of Education, Science and Technology with a strong incentive to find ways to offset the decline in order to maintain the size of its responsibilities and make efficient use of its infrastructure. One way to do this is to increase the age range of children included. The most logical expansion is downward. This also is consistent with the law for one year of free kindergarten education. The same holds true for private kindergarten's as they face a declining population and must compete harder to increase their market share if they want to maintain or increase their size. Many young children are already served by childcare centres, which also experience a need to compete to increase their market share. Even kindergarten enrolment has declined slightly since 2000 despite an increase in the percentage of that age group enrolled in kindergarten.

The pressures and likely responses from the Ministry of Health and Welfare 
responsible are similar to those for education. What is different is that childcare enrolment of children under age five has increased massively from 2000 to the present in sheer numbers (from 686,000 children in 2000, 989,390 in 2005 to 1,348,729 children in 2011). The mission of the Ministry of Health and Welfare is focused on disadvantaged children, but the reality seems to have become that childcare services are offered to children from all backgrounds. One might suppose that this could be a problem for the Ministry of Health and Welfare as whole, because it seems likely that the growing elderly population will create financial pressures on the Ministry as a whole, and may increase the scale of its responsibility) ${ }^{5}$. Although the total Korean health care expenditure at $6.9 \%$ of GDP is still well below the OECD average of $9.5 \%$, health care expenditures in the Republic of Korea have been rising as a share of government expenditure in recent years at nearly twice the rate of the average rise across OECD countries (OECD Health Stats, 2011).

\section{Competition and Its Impact on Equity and Quality in the Parallel System}

The UNESCO team encountered a view that competition between kindergarten and childcare had positive consequences. The notion of competition is associated with choice for parents, meaning that childcare services and kindergartens compete to attract parents by meeting their wishes, needs and interests, such as the best education for their child and most convenient hours for each family. As children and families vary in their needs, this should result in somewhat diverse services. Most parents do appear to have choices between providers that would allow them to take into account the needs of a particular child's development and temperament. Also, the hours of most providers meet the desires of parents for long-hours of care and many days per year whether the programme is a kindergarten or childcare.

However, some things are easier for parents to see than others. Location, facilities, hours, and specific activities offered are easy for parents to see and compare so that they may tend to be emphasized by providers over aspects that are important but difficult for parents to see (such as the effectiveness and frequency of teacher-child interactions). The long hours that teachers work raise concerns about their effectiveness both because they may become fatigued and lack adequate planning and reflection time. If fees are lowered by reducing quality (as opposed to innovation and increased efficiency, for example), this would likely occur in ways that parents were least able to see the consequences for quality. It may be very difficult for parents to judge differences in the quality of education provided. As a result, parents may make less than optimal choices and competition may push programmes toward services that are less beneficial for child development than otherwise. 


\section{Low Income Families and the Parallel System}

Undoubtedly, access to ECCE in Korea has been facilitated by the declining population, economic growth, and increases in government support. Nevertheless, there may be some families who are not obtaining the quality of ECCE that they would like because it is not affordable for them. There may also be families who do not participate at all because they have very low incomes and cannot access free services in their location.

However, the statistics show that $8 \%$ to $9 \%$ of children at the age of 5 do not access any early childhood service. Different explanations were given concerning who these children were (research seems to be limited on the issue). Some of them are children who are too poor to participate in services: their parents cannot afford enrolling children in ECCE services because of supplementary costs, such as clothes, meals and field trips. This is an issue that requires more research and, if true, upstream government action.

The concerns for differential quality between kindergarten and childcare are deepened when parents choose based on price (net of subsidy) to them and hours of care. Even though government addresses this issue by providing higher subsidies for tuition to low income families, this may not completely equalize opportunities by income, and there are other fees and costs to participating in kindergarten and childcare.
The percentage receiving subsidies for low-income in kindergarten and childcare suggests that low-income children are more likely to be in childcare, which may be the lower quality sector (judging from teacher salaries and cost per child).

In addition, research indicates that low-income children learn more when they attend programmes with higherincome peers, but if low-income children are largely in separate programmes such mixing will occur infrequently. As the social benefits are likely to be larger for lower income children, these factors that lead to lower quality for children from lower income families not only tend to increase inequality, but are costly to the nation's long-term economic well-being and quality of life.

\section{Workforce and Quality Assurance in the Parallel System}

There are important differences in teacher education standards between the government agencies responsible for childcare and kindergarten in the Republic of Korea. Kindergarten teaching requires higher levels of educational preparation and public kindergarten teachers are chosen through a preliminary competitive examination. In addition, kindergarten teachers, particularly public kindergarten teachers, are paid considerably more (and receive more benefits) than other ECCE teachers. Thus, there is an overall problem with teacher compensation across the ECCE sector, unlike remuneration in primary and secondary education. Since relatively 
few children are served in public kindergarten, this raises a concern for quality system-wide. Private childcare and family home daycare providers are less qualified and are paid considerably less than private kindergarten and public childcare teachers.

Although the empirical literature is mixed regarding the effects of teacher compensation and pay on quality, suggesting that it matters significantly only under certain circumstances, it is also true that large educational gains for children have been found only for ECCE systems staffed with relatively well-paid professionals. Economic theory strongly suggests that whenever programmes compete for teachers in largely private systems, better teachers will be drawn to sectors with better compensation and working conditions.

\section{An Analysis of Integration Options for the Republic of Korea}

Further improvements in the integration of care and education could be pursued through (a) coordination of the current parallel systems, (b) a split system by age groups, (c) integration of all services under a single ministry, (d) integration of all services under a new central agency, and (e) integration through devolution to local authorities.

\section{Coordination of the current parallel} systems is one path to improving quality. Coordination of parallel systems operated by the Ministries of Education and Health and Welfare will require cooperation between the two agencies. A set of policies and programmes that together meet the needs of young children and families of the Republic of Korea could be jointly developed. An example of such coordination is the development of the Nurri Curriculum for Age 5 together with policies for implementation, training of existing teachers, preparation of new teachers, and evaluation. This example is an important test case. Coordination is more difficult and time consuming than if one agency was in charge. The cost is modest relative to the overall budget and potential benefits as it consists of the time of agency staff for coordination at the national and local levels. If agencies are not provided with resources for this activity then time will be taken from other responsibilities. To facilitate coordination, a council or committee could be formed with representatives of each agency (at local as well as national levels). The United States is an example of a country that has developed such organizations at the state level to facilitate coordination.

The most important challenge with respect to coordination is to raise both systems to the highest standard of either rather than dropping one down to the other when a common policy is desirable and to allow differentiation when the parallel systems usefully meet different needs. Agencies may disagree about which is the case. The question then becomes whether a good solution is found or coordination 
breaks down and no progress is made. The situation is made more difficult or easier by the extent to which sound evidence is available. For example, in the United States it is sometimes said that the kindergartens are better at enhancing cognitive development and the childcare programmes better at enhancing social-emotional development, or that the kindergartens provide services that are more attractive to higher income families while the childcare centres provide services that better meet the needs of low-income children. The only way to resolve such claims is to obtain relevant data and conduct studies that would allow one to determine with some confidence whether such statements are true. To obtain such data, it may be necessary at the very least to create a unified or joint agency with funding and authority to collect data across agencies. In the United States, state level councils with broad representation from both education and childcare sectors and other agencies have been formed with just such a purpose. In other countries, national studies have been commissioned to obtain data across all sectors, but they have not necessarily been this broad in terms of the data collected.

\section{Splitting the ECCE system by age is} not agreed upon and could have negative consequences. This was suggested by some people with whom we discussed the potential integration of care and education in the Republic of Korea. There is a lack of consensus about what the age split should be, with some indicating birth to 2 and 3 to 5 , and others birth to 4 with 5-year-olds separate. An age-split system has some advantages if there are gains to specializing in care for younger children and education for older children. This is likely to be true when education for three to five year olds is defined narrowly as including only methods and content that are similar to those of the primary school. It is true that children at these ages benefit from instruction as part of their activities and from coordination of the curriculum with that of the primary school. Yet, the first three years of life, just as the next three, is a time when children benefit from education which is broadly defined rather than narrowly academic.

In addition, we encountered the opinion that competition between the two systems had increased the integration of care and education within each part of the system and allowed parents more choices. Changes in recent years would seem to bear that out. Breaking the system apart by age might remove the competitive pressure to integrate care and education. It might also reduce the choices available to parents. While it may be beneficial to eliminate choices for parents where the quality of education is too low, additional choice is generally a benefit. Of course, choice can have a cost if it results in more small operators who have higher costs than larger operators. It seems likely that expanded choice incurs some additional costs and that these would be reduced by coordination across an 
age-split system compared to the current parallel system. Nevertheless, the vast majority of costs are accounted for by the teachers and assistants and the space for each child, so it is unlikely that cost savings from splitting the system would be large. It could be much smaller than lost benefits if the effectiveness of ECCE declined and parent choice was reduced.

\section{Integration of All Services Under a Single Ministry}

A brief examination of the experiences of countries such as England, Iceland, New Zealand, Norway, Slovenia, or Sweden suggests that greater progress is made when a central vision is put at the centre of ECCE policy, and a dedicated ministry is nominated to translate this vision into reality. Even if the final result is not fully satisfactory, as in the case of England (where a largely unrestricted for-profit private sector still exists), there is little doubt that the achievements of the last 15 years would not have taken place had not one ministry been firmly in control. A lead ministry at national level can also address the care and education of young children from birth to 6 years more holistically and coherently, with an integrated approach to staffing, financing, regulation and monitoring. Various analyses, including the OECD reviews, show the advantages that flow from bringing policy-making under one agency:

- More coherent policy and greater consistency across sectors in terms of regulation, funding and staffing regimes, curriculum and assessment, costs and opening hours, in contrast to fragmentation of policy and services;

- More effective investment in young children, with higher quality services. In a split system, the younger children are often defined primarily as dependent on parents or simply in need of childminding services. As a result, their services have often to make do with insufficient investment, nonaccredited childminding and unqualified staff;

- Enhanced continuity of children's early childhood experiences as variations in access and quality are lessened under one ministry, and links at the services level across age groups and settings are more easily created;

- Integration within education generally brings added advantages, such as, better training, work conditions and remuneration for the workforce. It also changes perceptions of ECCE among the workforce, parents and the wider public, including greater recognition of its pedagogical value.

One conclusion of Caring and Learning Together (Kaga, Bennett \&Moss, 2010) was that integration means re-thinking and re-forming:

Deep integration, bringing about a major change in ECCE services, requires re-thinking as well as reforming structures. A range of 
major structural changes are needed, involving areas such as funding, regulation and workforce. But these need to be accompanied and supported by new thinking, which give the structural changes a clear rationale, a clear direction, and a clear momentum. One part of that thinking - the concept of education has already been mentioned and will be returned to. But it needs to be accompanied by new thinking about other key concepts and subjects, e.g. understandings of care, learning, children, workers and services.

An important part of re-thinking, therefore, is the development of integrative concepts, concepts such as 'pedagogy' and 'education in its broadest sense', that is, ways of thinking about ECCE that go beyond the 'childcare'/'early education' divide. Integrative concepts and integrative structures are mutually reinforcing (p. 116-7).

Another conclusion of the same study was that there were no widespread or substantive negative consequences of integration. All six cases of integration examined reported positive consequences, especially for the position of children under three years, but also in terms of curriculum development and pedagogical work. In only one of these cases, namely Sweden, the concern about 'schoolification', that is, the downward pressure of the school system and its methods into the ECCE system, was raised.
However, agency history and culture are such that, even with the best intentions, ministries may continue to pursue past goals and objectives even after being given a different one. Therefore, it is likely to take time, willingness and efforts to move toward deeper integration, both conceptually and structurally, regardless of which ministry is to be assigned the responsibility for all care and education services.

\section{Integration of All Services Under a New Agency}

This is possible, but where would the new agency be located? Could it be jointly funded and administered by both agencies, or would it be completely autonomous? If jointly administered, it can be considered a strong version of the coordination option. If given sufficient autonomy, such an agency could reduce the costs of developing policies and reaching consensus. The new agency could have advantages in developing stronger integration of care and education while improving the quality of both. This would depend on making best use of the existing people and other resources of the current parallel system and bringing them together in a new more unified vision.

\section{Integration of All Services Through Devolution to Local Authorities}

One needs to distinguish here between decentralisation to ministry local offices (as is the case, for example, with the present Ministry of Education, Science and Technology and local offices of education in Korea) and real 
devolution of local policy, organization and management of early childhood services to local authorities, while retaining national policy, frameworks, regulation, national evaluations, monitoring and research at central level. Such devolution requires, of course, the allocation of sufficient financial resources.

This was the means employed by the Nordic countries to establish strong early childhood systems, sensitive to local needs, but under the policy direction and supervision of the central government. In turn, because the local authorities were relatively small, they brought together - for reasons of efficiency-the administrationof childcare and education. Over the years, the separate committees for each sector were merged and common goals were created as administrators and professionals from the two systems worked side by side. A common concept of pedagogy emerged bringing together care, upbringing and education. At first, the central coordinating ministry was social welfare, as in the 1970s, child poverty and social status of minority populations remained a challenge in these countries. As welfare issues for children lessened, raising the quality of early education became a priority. For this reason, the management of early childhood services was transferred to education: in Iceland in 1986; in Sweden 1996, in Norway 2006 and now in Denmark, October 2011. In Finland, ECCE still remains within the social welfare sphere, although discussion about bringing these services under the management of education are taking place in many local authorities.

The advantages of integrating ECCE services at the local level are many. Devolution helps to adapt services and resources to community needs, as it is generally recognized that early childhood policy and organization needs to be geared closely to parental needs and local circumstances. Depending on the context, integration can also encourage more efficient use of funding and cooperation across districts to innovate and share resources. Yet, while generally useful and necessary, the devolution of early childhood decision-making to local authorities can also lead to fragmentation and uneven implementation of national policies- a phenomenon that is further amplified by a lack of resources or by weak central monitoring.

The option requires, however, a revision of present local government arrangements, which would devolve responsibility for the sector to the local governments rather than to decentralised ministry offices. The UNESCO team learned that the level of autonomy given to local ministry offices, particularly in Education, was modest. In Busan, $98 \%$ of its education budget and $99 \%$ of its health and welfare budget comes from the central government. The Ministry of Health and Welfare funding is earmarked for childcare, but local education offices are free to decide on the proportion of central funding to be allocated to 
kindergarten education. The team was also informed that local education offices had little autonomy in terms of monitoring and supervision, and that they depended on the Ministry - unlike local health and welfare offices which depend on the municipal governments. A further variation on devotion could also be envisaged, namely, for local governments to integrate services while retaining the dual supervision and support of both the Ministry of Health and Welfare and the Ministry of Education, Science and Technology. In this way, young children could receive enhanced funding, allocated by both ministries. Above all, children's services would benefit from the expertise of the Ministry of Health and Welfare in matters of nutrition and health for young children and social assistance for families. This seems to be the thinking behind the UK House of Commons (2010) fifth review of Sure Start and Children's Centres ${ }^{6}$ where it is stated:

We believe that it was a backwards step to end formal Department of Health responsibility for the Sure Start programme at ministerial level, a situation which has carried over to Children's Centres. This is clearly not the only reason why local health services are not consistently involved in Children's Centres either strategically or operationally - there are many practical and professional reasons why collaboration is difficult. Nonetheless, the Government should lead from the front by establishing joint the DCSF [Department of Children, Schools and Families] and Department of Health responsibility for Children's Centres. The first task of the Ministers who take on this role should be ensuring that Children's Centres are prominently and consistently reflected in both Departments' policy priorities and performance frameworks.

It is easy to understand why this regret was expressed in Parliament in the United Kingdom. Unlike Finland, which has very low child poverty rates, high levels of child poverty exist in the $\mathrm{UK}^{7}$. In such a situation, the access to health services ofmothers and young children becomes critical as does the funding of expanded and/or comprehensive services $^{8}$ in kindergartens and schools. At the same time, the primary goal of Children's Centres and of early services in general is educational, both vis-à-vis the children and their parents.

\section{Conclusions and Recommendations}

A brief visit and review of the Korean ECCE system provides a limited basis for recommendations regarding policy changes. As a result, only a few recommendations are put forward, which address issues about how to go about decision-making, rather than advocating policies to be adopted. 
While not ignoring potential administrative cost savings and increased efficiencies from larger programmes due to economies of scale, the primary focus should be on the potential benefits to children and Korean society as a whole from improvements in coverage (still relatively unequal) and in the quality of care and, especially, education within both sectors. The potential benefits of improving quality are probably much larger than any potential cost savings from administrative reform. This is particularly true because the rapid expansion of the childcare system has opened some gaps in quality, which suggests that one urgent need in this part of the system is to expand administrative and support infrastructure.

The first principle for decisions about the administration of the ECCE system should be that they begin with an analysis of the most important needs for improvement and how these might be addressed. Our brief review suggests several key issues:

- A multi-tiered system disadvantages low-income families, substantially reducing the economic benefits of government subsidies for ECCE and increasing future inequality.

- A relatively high reliance on fees also tends to increase inequality and discourages parents from having more children.

- At the administrative level there is some duplication of effort and decision making can be slow and expensive when agencies must agree on coordinated plans.

- Lack of coordination across agencies can raise costs for the private sector unnecessarily if providers must comply with regulations from multiple agencies.

Consideration should be given to further reducing the fee burden on parents, particularly for lower income families, if it is found that affordability adversely affects decisions about participation and equal access to quality. At the same time, increased subsidies are needed to equalize quality across the sectors generally. As resources are limited, there is need to balance efforts to reduce the fee burden on parents with efforts to increase quality. The economic benefits to the nation as a whole depend on ensuring that all ECCE is of sufficiently high quality.

Consideration could also be given to the feasibility of turning private services into semi-public services as a way for private services to receive public support and subsidies comparable to what public services receive at present. However, as in England, this may be difficult to achieve; much depends on the size of the private sector, its desire for cooperation, and its willingness to forgo profit. Other countries have managed better the private-public divide, for example, Norway where private providers - who take in charge rather more than half of Norway's children are obliged to cap their fees at a nonprofit level and comply with the 
licensing and quality criteria set by the Ministry of Education. The United States also offers examples of private providers competing to provide ECCE services and offering parents choices but at high quality levels set by education departments where government pays the vast majority of the costs and parents pay only small fees for extended hours (as in New Jersey's "Abbott" programme) (Barnett et al., 2011).

More information is needed about the quality of services, both public and private, delivered across agencies whether and to what extent they contribute to child well-being, learning and development, and whether they meet the needs of parents. Such information would inform decisions about how best to improve services and would help to better coordinate the existing parallel systems or to opt for the integration of ECCE services under one agency. Empowering and funding a single agency to collect such data across systems could provide vital information to inform coordinating or integrating agencies and their policy.

Continued collaboration on the effective implementation of the common curriculum for 5-year-olds is likely to pave the way to greater coordination and integration across the childcare and kindergarten sectors. In addition to joint elaboration of the common curriculum, joint curriculum implementation - which would include joint training of childcare and kindergarten teachers as well as joint support and monitoring mechanisms - can be recommended. Similarly, the continuation and expansion of the Yeong Cha Project can be recommended, as it contributes to a bottom-up sharing of understanding, goals and practices vis-à-vis young children, regardless of their age, background or the setting in which they receive care and learning.

\section{References}

Barnett, W. S., Carolan, M. E., Fitzgerald, J., \& Squires, J. H. (2011). The state of preschool 2011: State preschool yearbook. New Brunswick, NJ: National Institute for Early Education Research.

Eurostat. (2011). European Commission. Retreived from http://epp.eurostatec.europa.eu/portal/ page/portal/eurostat/home/(accessed 28 October 2011).

Kaga, Y., Bennett, J. and Moss, P. (2010). Caring and Learning Together: A CrossNational Study on the Integration of Early Childhood Care and Education within Education. Paris: UNESCO.

Karoly, L. A., Ghosh-Dastidar, B., Zellman, G., Perlman, M., \& Fernyhough, L. (2008). Nature and quality of early care and education for California's preschoolage children: Results from the California Preschool Study. Santa Monica, CA: Rand.

Korea Institute of Child Care and Education (KICCE). (2011). Key figures on early childhood education and care. Seoul, Korea: KICCE.

Haskins, R. and Barnett, W. S. (2010). Investing in young children: New directions for federal policy. Washington, DC: Brookings Institution.

House of Commons. (2010). Children, Schools and Families Committee, Sure Start Children's Centres, Fifth Report of 
Session 2009-10, Volume I Summary. UK: House of Commons Publications.

Ministry of Health, Welfare and Family Affairs. (2009). National Survey on Childcare. Seoul, Korea.

Moon, M., Kim, E., Kim, J., Hwang, H., Moon, H., Kim, M. \& Yang, S. (2009). A Pilot project for collaboration between kindergartens and childcare centres(The Yeong Cha Project): Achievements and future taskes. Seoul, Korea: KICCE.

Moon, M., and Suh, M. (2011). Integration of Early Childhood Care and Education Policy: Country Background Report of the Republic of Korea. Unpublished paper.

OECD. (2001). Starting Strong: Early Childhood Education and Care. Paris: Author.

OECD. (2004). OECD Country Note: Early Childhood Education and Care Policy in the Republic of Korea. June 2004. Paris: Author.

OECD. (2006). Starting Strong II: Early Childhood Education and Care. Paris: Author.

OECD. (June, 2011). A framework for growth and social cohesion in Korea. Retrieved from http://www.oecd.org/dataoecd/37/2/ 48225033.pdf (accessed28 October 2011).

OECD. (2011). Society at a Glance. Paris: Author.

Rhee, O., Kim, E., Shin, N. \& Moon, M. (2008). Developing models to integrate early childhood education and care in Korea. International Journal of Child Care and Education Policy 2(1), 53-66.

Suh, M. and Kim, E. (2010). Early Childhood Education and Care Policy in Korea. Seoul, Korea: KICCE.

\section{Notes}

1 That is, systems where there is parallel or overlapping responsibility for age groups served by the education, health and social affairs ministries or departments, mostly in the two or three years before school entry.

2 The report on the study is available: http:/ / www.unesco.org/en/early-childhood/publications/

3 Hakwons are private academies run by individuals and teach students with subject matterrelated knowledge, skills and arts. Most 'hakwons' for young children teach art, playing the piano, gymnastics as well as Korean language fundamentals, English, arithmetic.
4 'Yeong Cha' has two meanings. One is the sound people make in the Republic of Korea when they join forces to achieve a shared goal. It is meant, therefore, to symbolize the concerted efforts made by participating stakeholders of the Project such as those working in childcare services and kindergarten, government offices and local communities. Secondly, 'Yeong' in Korean means 'zero' in English. This gives the Project the meaning of eliminating the gap between kindergartens and childcare services in terms of quality so that all Korean children are provided with quality service.

5 The Republic of Korea is rapidly aging, having an increasing number of elderly, which accounts for a rising share of national income. By 2050, its elderly dependency ratio is projected to be the second highest in the OECD area (A framework for growth and social cohesion in Korea, OECD, June 2011).

6 Children, Schools and Families Committee, Sure Start Children's Centres, Fifth Report of Session 2009-10, Volume I Summary (House of Commons, 2010).

${ }^{7}$ According to the most recent child poverty research by Save the Children, 1.6 million children across the UK live in severe poverty. In 29 local authorities, more than one in five children live in severe poverty, rising to over $25 \%$ of children in Manchester and Tower Hamlets.

${ }^{8}$ Expanded services include meals, longer hours, health screenings and referrals, and regular liaison with social and family services. 